\title{
EFFECTIVE INTEGRATION OF NASA STEM CURRICULA IS ALLOWING STUDENTS TO APPRECIATE EARTH SCIENCE CONCEPTS
} \section{THE IITY UNIIERSITY OF NEW YORK}

NASA Minority University Research and Education Project (MUREP) Aerospace Academy - MAA is a national, innovative activity designed to increase participation and retention of historically underserved and underrepresented K-12 youth in the STEM disciplines, particularly earth science and human exploration (HEO). HEO is dedicated to informing and educating the public about NASA's plans for a new era in space exploration. Utilization of NASA satellite images, online climate education, space mathematics and other earth science-related resources is allowing students to conduct basic research and prepare themselves for a New York City-wide science competition. In addition to offering school children a solid grounding in STEM and increasing the involvement of parents in their children's education, MAA at York fulfills many other important community needs. The majority of our MAA parents are immigrants and ESL people who greatly benefit from the program in terms of obtaining critical STEM education opportunities for their kids. The MAA Family Café allows them to locate, source, easily navigate and retrieve pertinent information and opportunities such as specialized high school admission, SAT, math and science tutoring, College Now Program, and most importantly online NASA educational resources for enhancing their understanding of STEM both for themselves and their kids. Family Café is certainly a venue where parents are also becoming STEM conscientious citizens and they often acknowledge the magical impact MAA did on their kids. Noticeable impacts demonstrated by many MAA students include higher performance in math and science tests, positive interest, renewed motivation, and curiosity. Pre-service teachers from the college also work for the program, thus in part fulfilling their fieldwork requirements and becoming better trained science teachers. Pre-service teachers are strongly encouraged to attend MAA classes, participate in STEM activities, and often guide students in the completion of tasks. With this close collaboration, pre-service teachers acquire an essential pedagogical component on formulating their own STEM activities and constructing a good lesson plan to achieve maximum effectiveness.

NASA MAA STEM Outreach Grant Funded This Project.

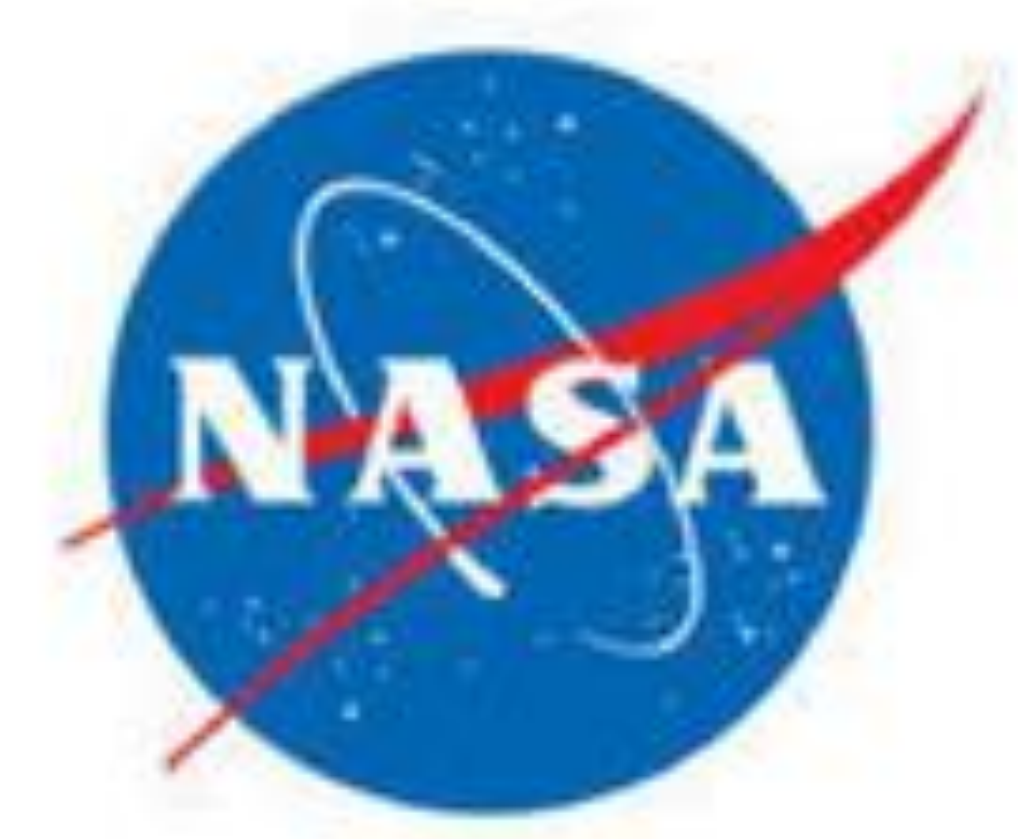
and
9. York College (CUNY), 94-20 Guy R. Brewer Blvd, Jamaica, NY 11451, nkhandaker@york.cuny.edu nkhandaker@york.cuny.edu
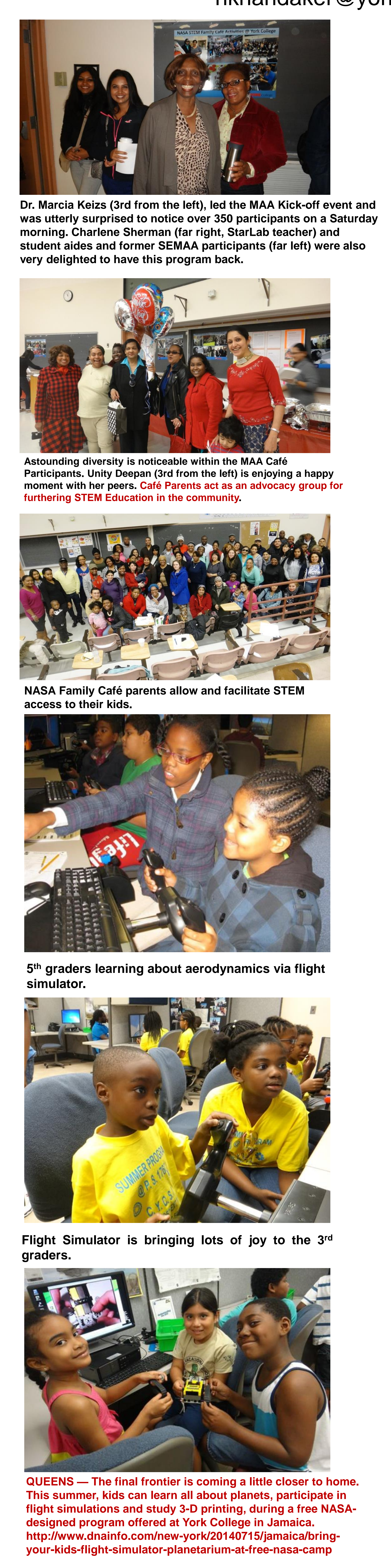
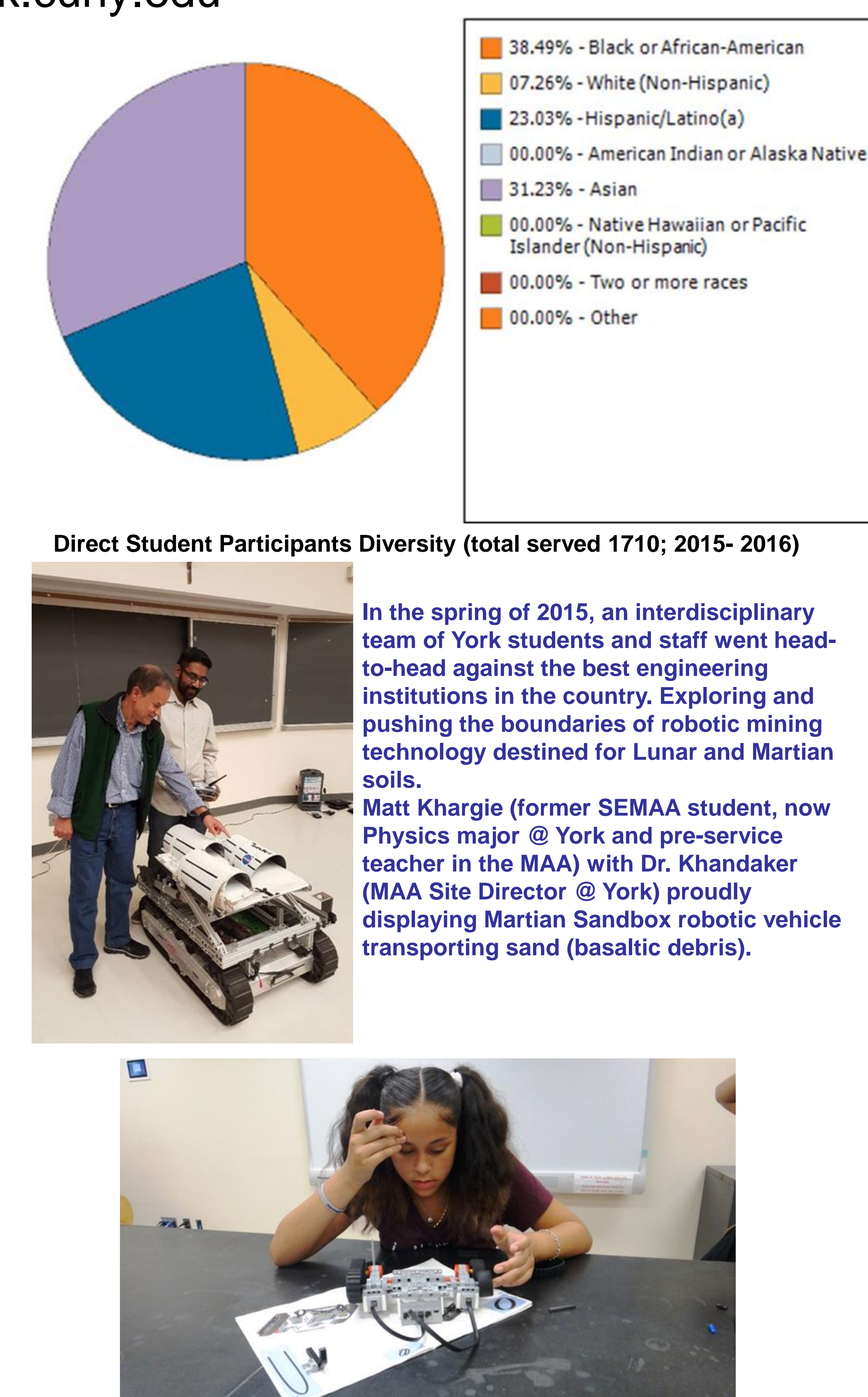

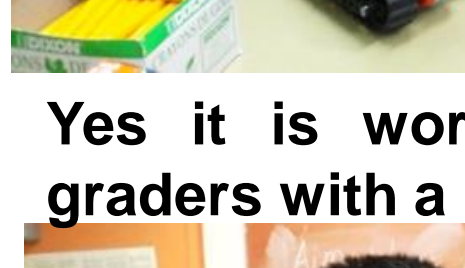
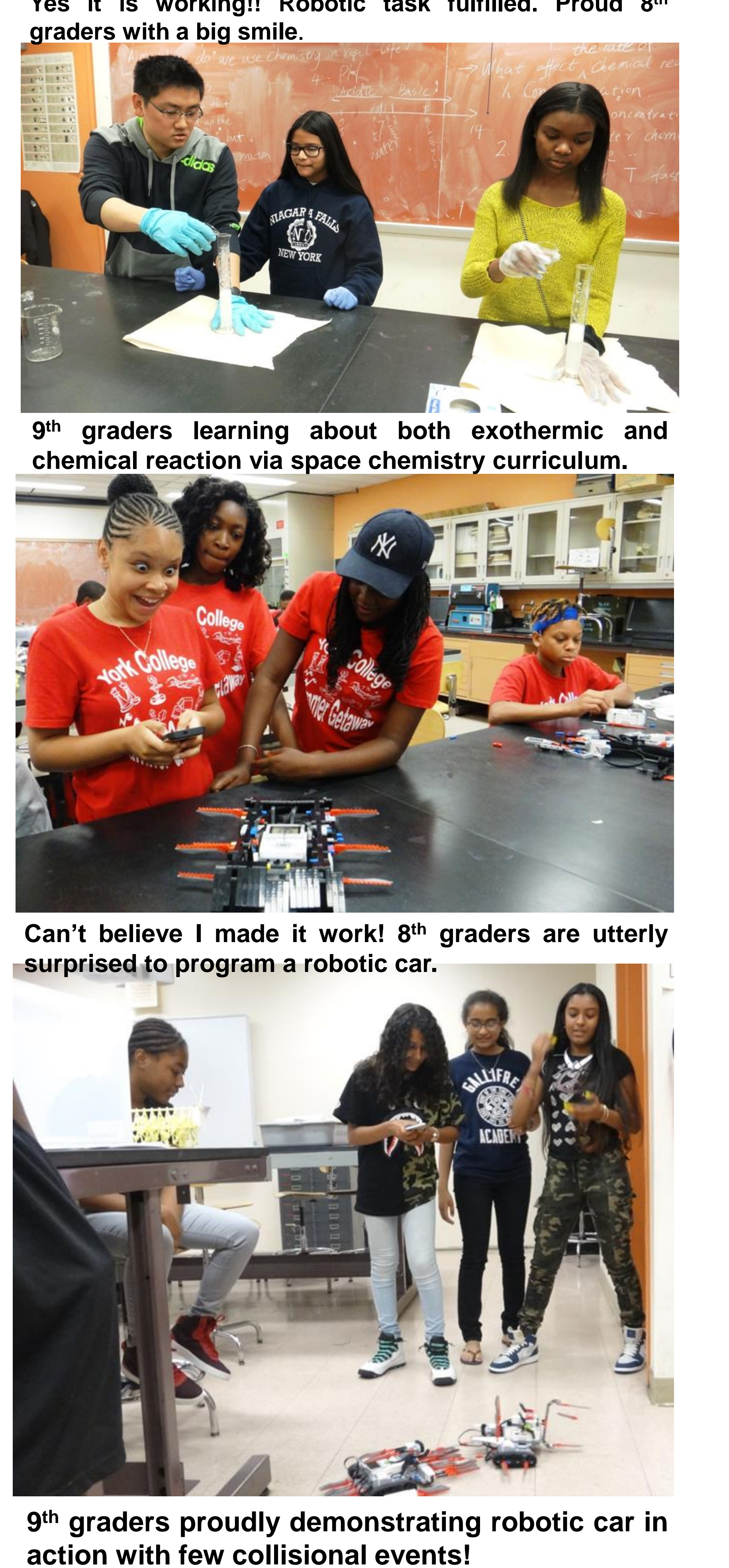

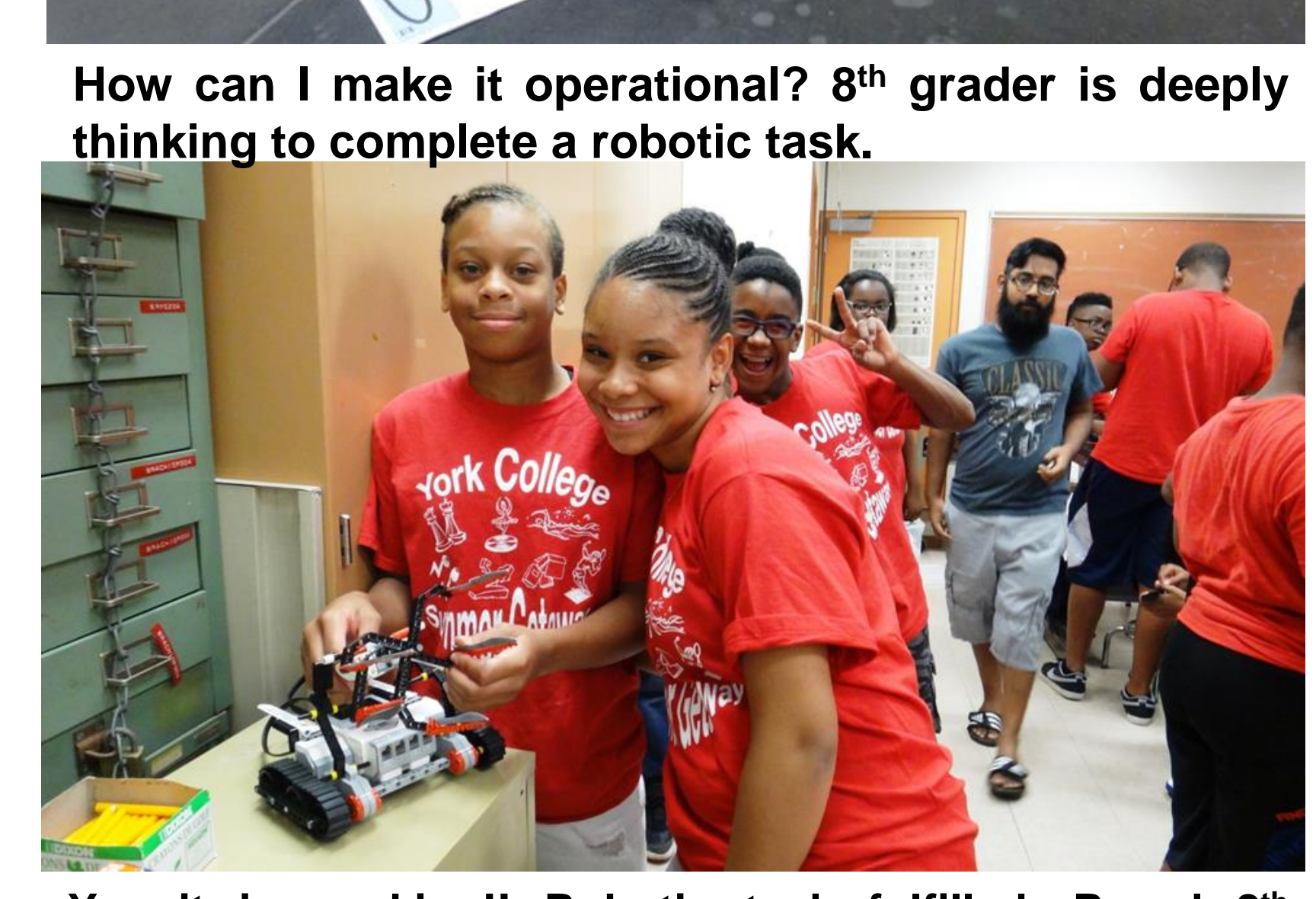

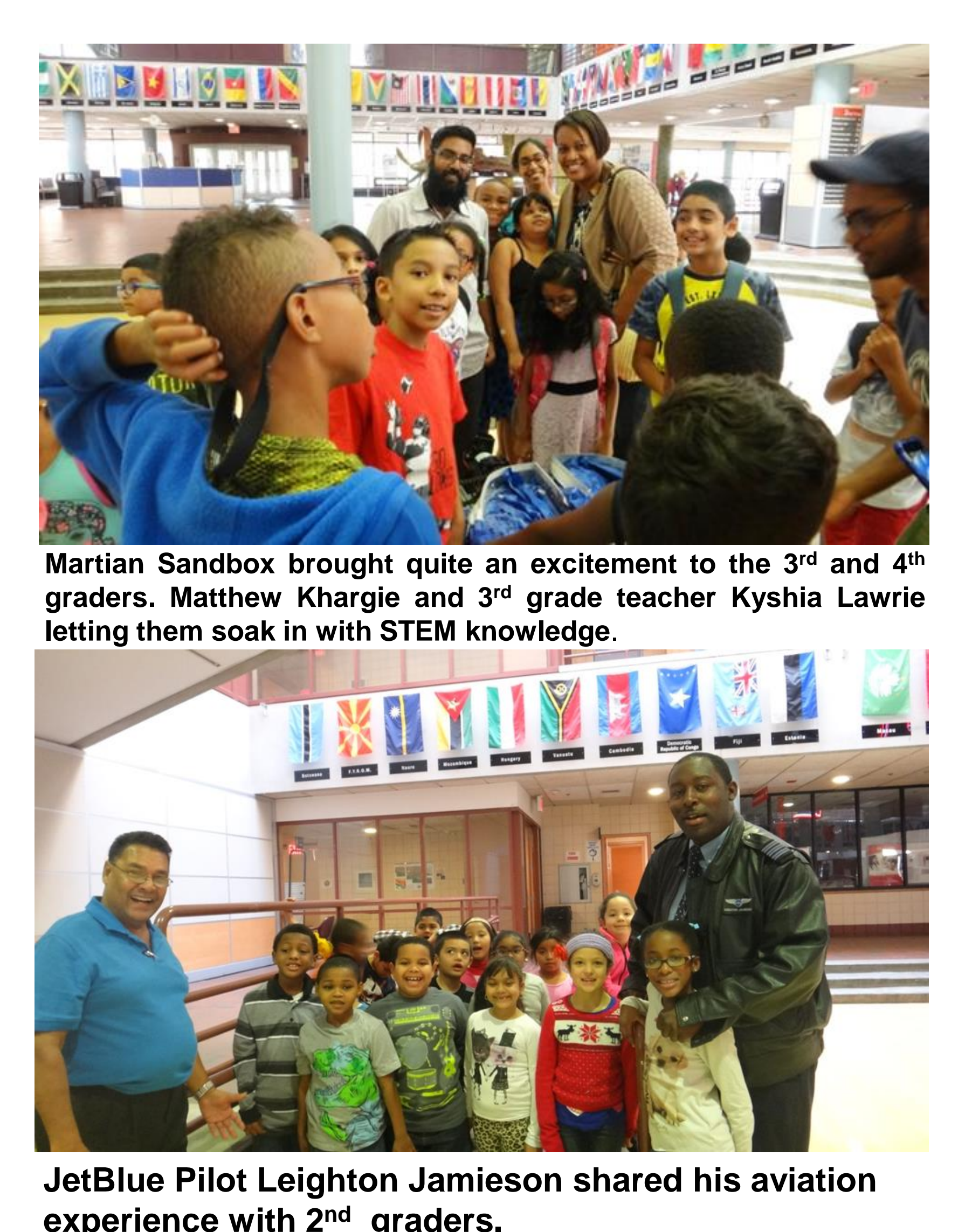
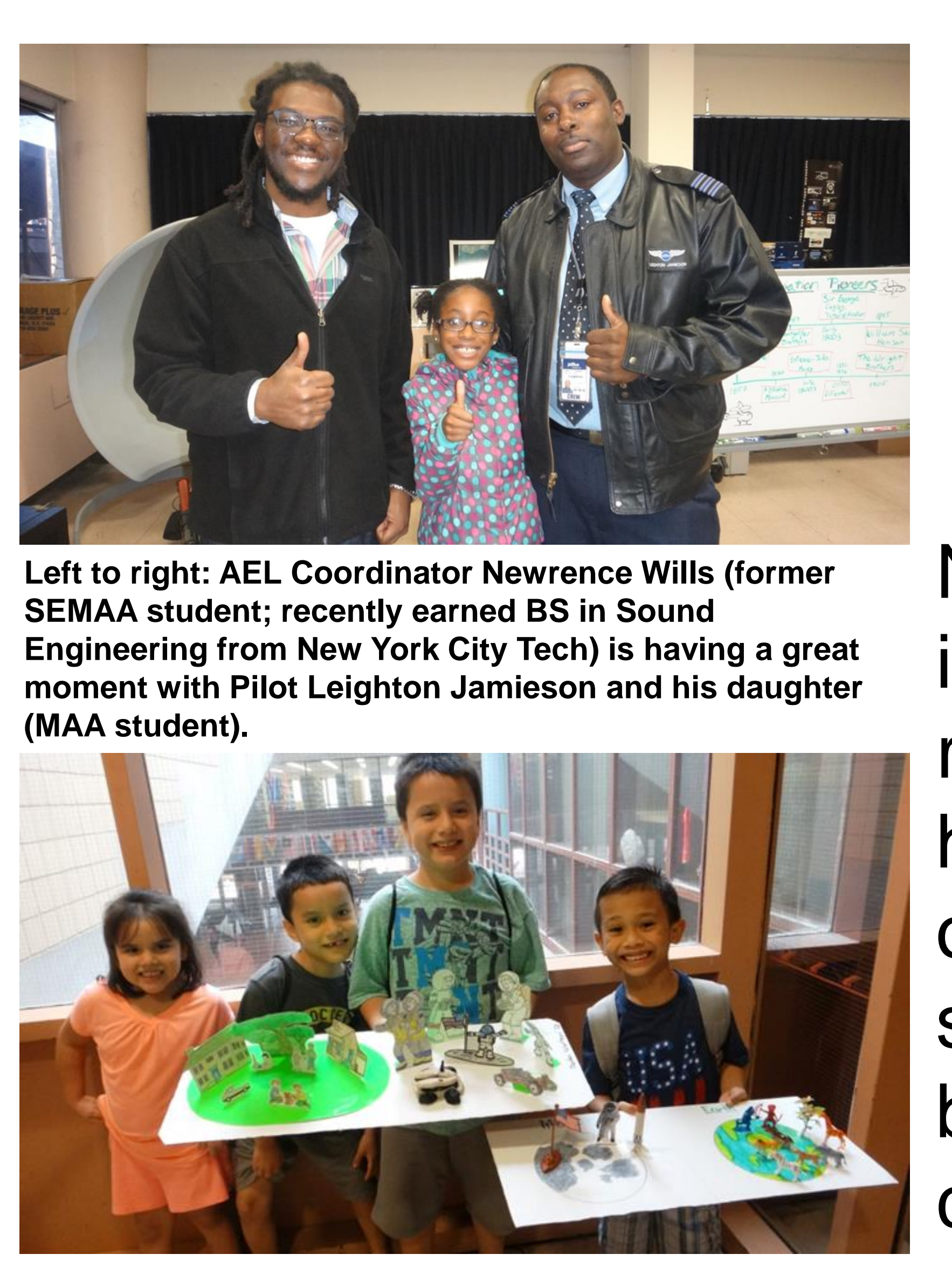

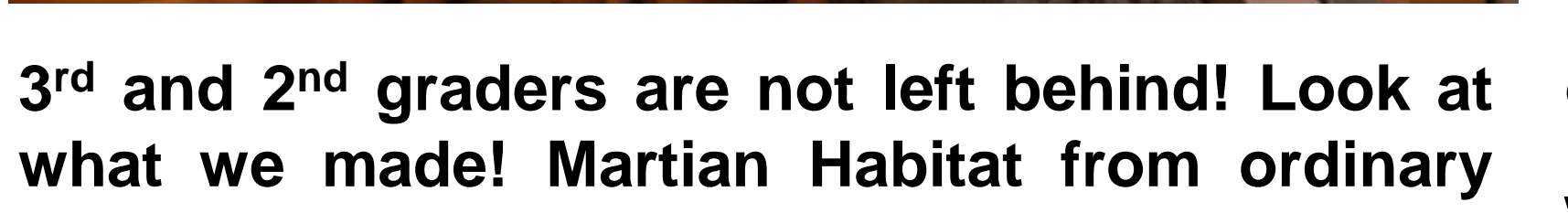
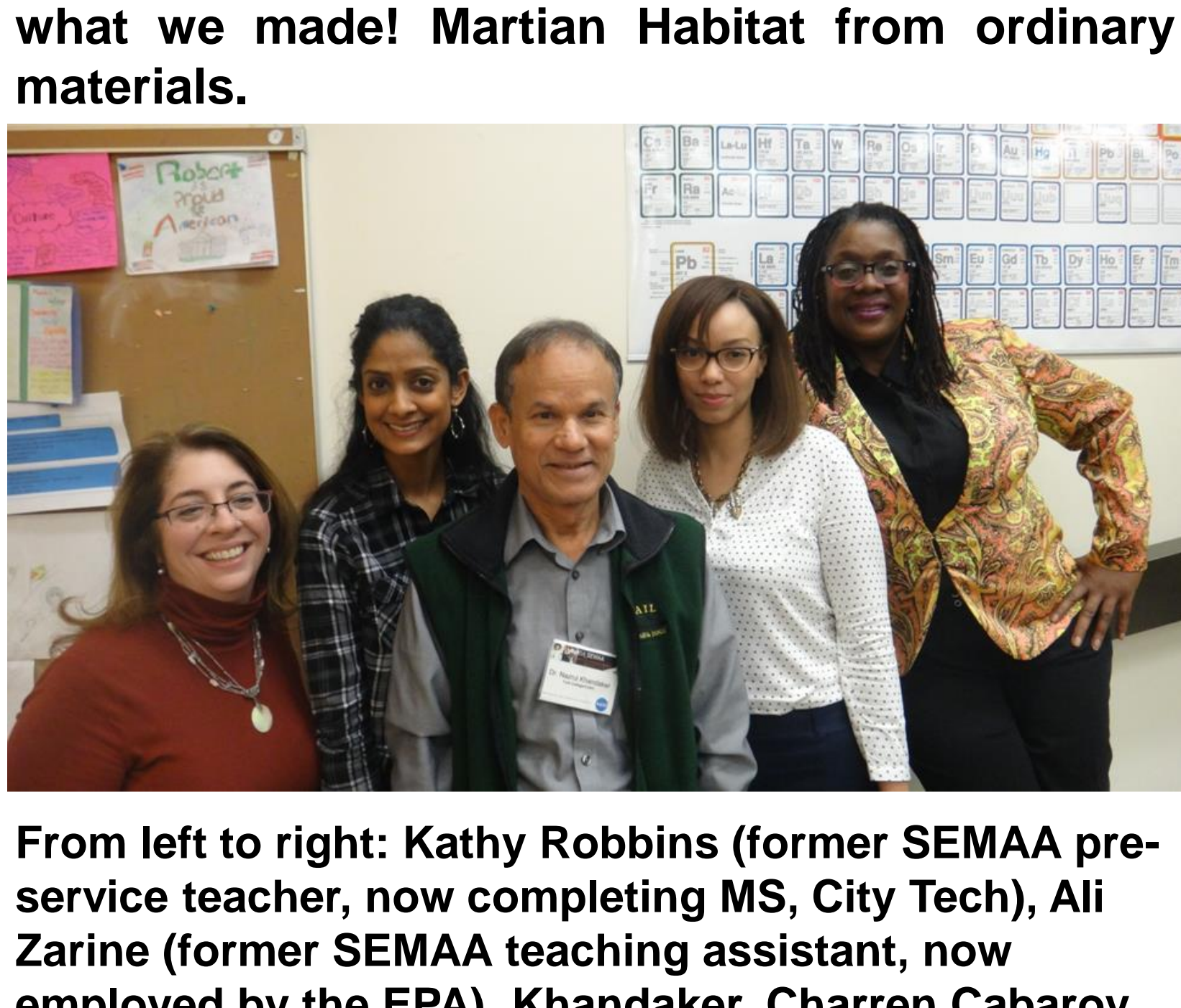

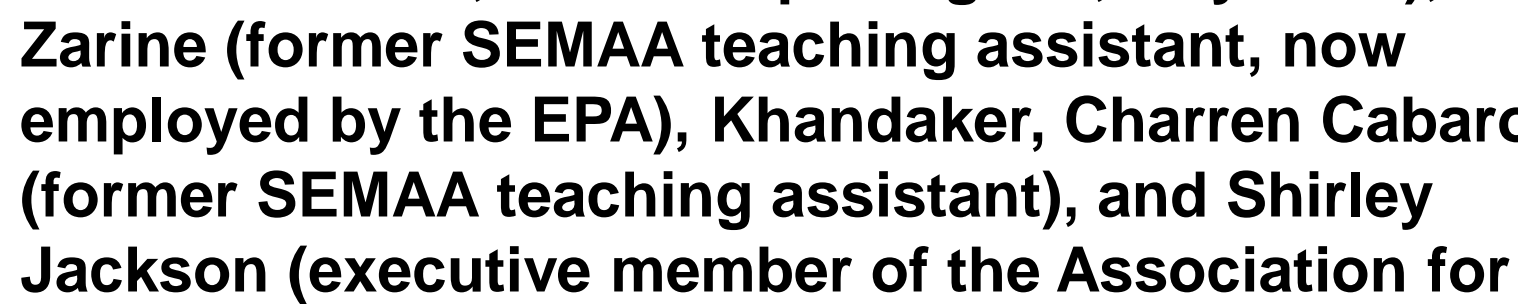
(former SEMAA teaching a
Jackson (executive member
Women Geoscientists; now

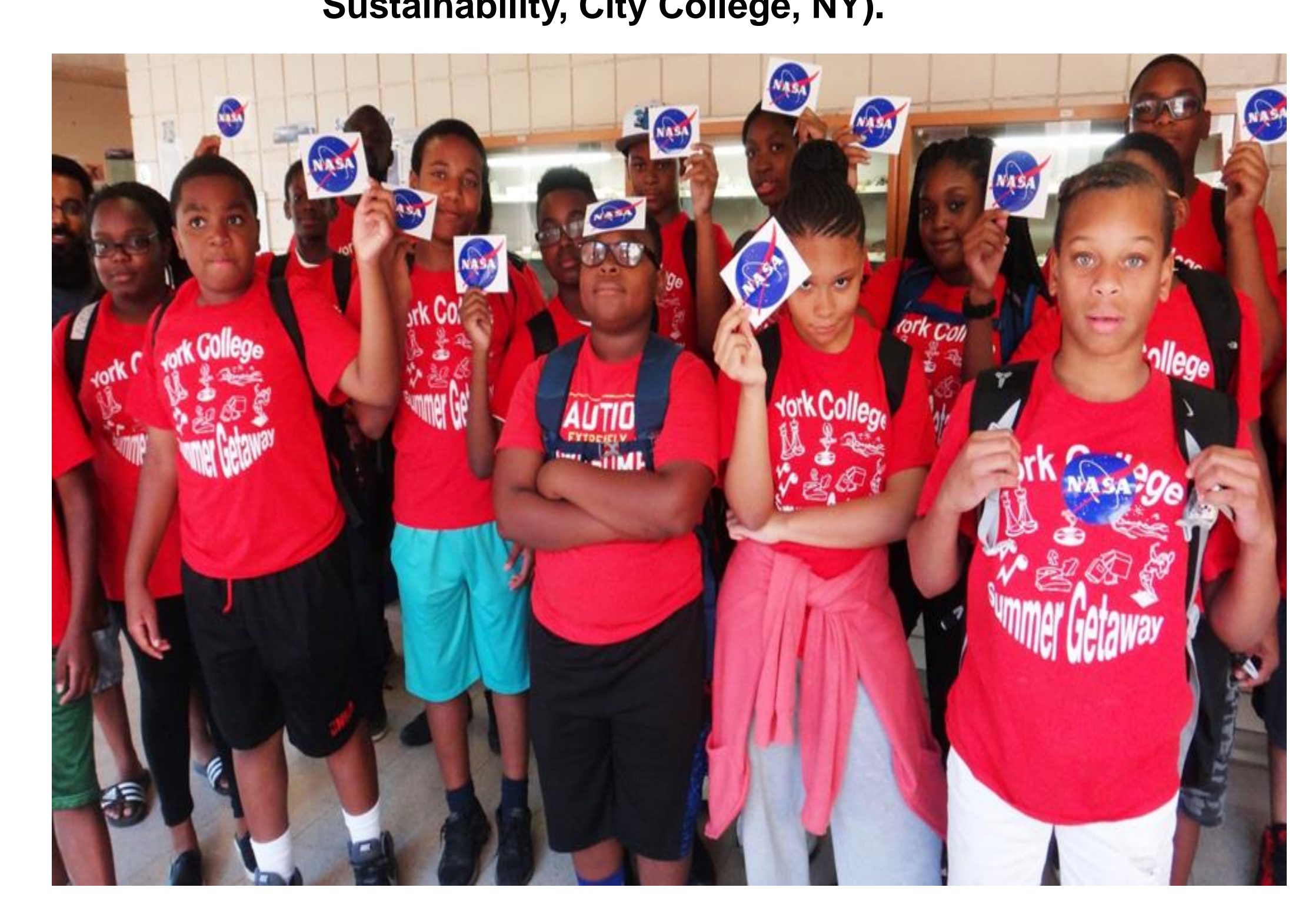

Grand finale and proud NASA students celebrating weeks of
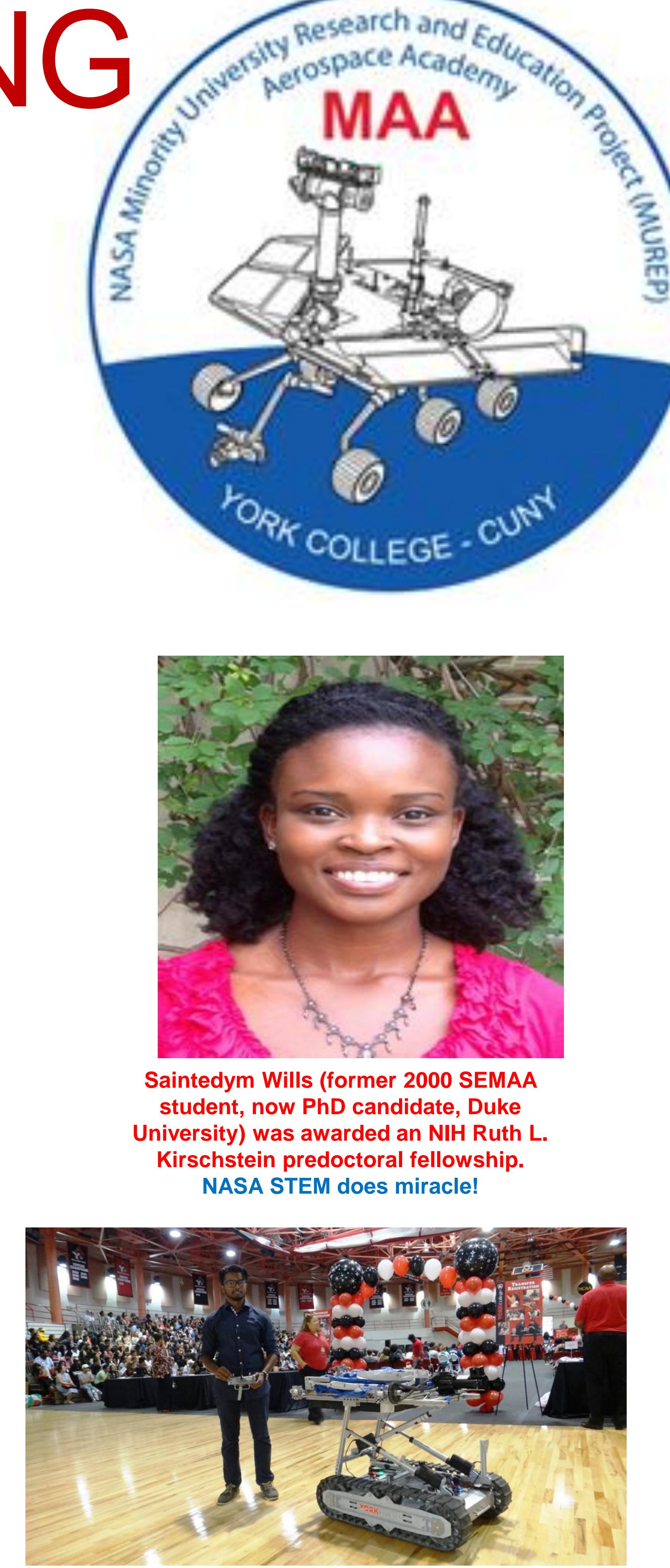

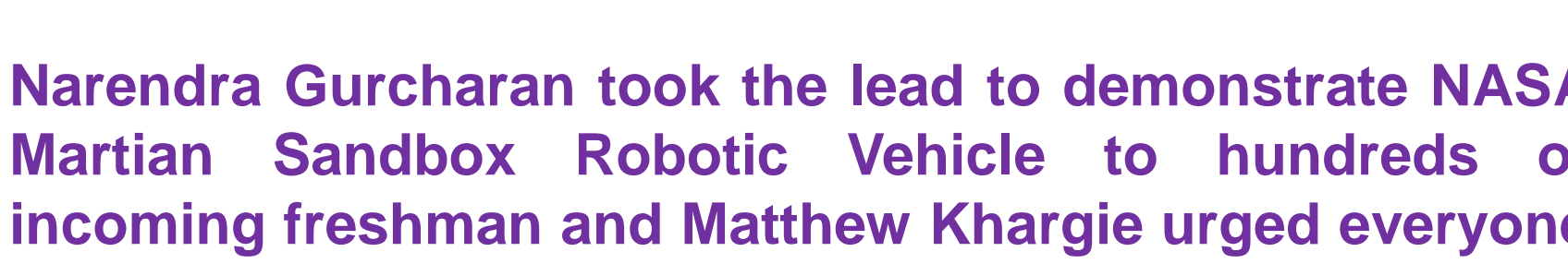

Conclusion

ASA MUREP Aerospace Academy is opening up an excellent online esource in addition to offering hands-on, experiential learning opportunity (ELO) to the younger students (K4-9) by allowing them to build rockets and various robotic components (EV3 Mindstorm). It also engages students to program, write code and conduct STEM experiments to fulfill their inner curiosity and unleash an outburst of energy full of excitement and readiness to embrace challenging tasks.

Integration of multidisciplinary STEM subjects coupled with ELO research activities at an early stage can play a pivotal role in motivating K9-16 students to appreciate the broader science contexts and their relevance to geosciences. From recruitment and retention point of view, it should be viewed as being of utmost academic importance. 